\title{
Preliminary Investigations into the Alteration of Cadmium Orange Restoration Paint on an Ancient Greek Terracotta Krater
}

\author{
Georgina Rayner ${ }^{1, *}$, Susan D. Costello ${ }^{1}$, Arthur McClelland ${ }^{2}{ }^{-}$, Austin Akey ${ }^{2}$ and Katherine Eremin ${ }^{1}$ \\ 1 Straus Center for Conservation and Technical Studies, Harvard Art Museums, 32 Quincy Street, \\ Cambridge, MA 02138, USA; susan_costello@harvard.edu (S.D.C.); katherine_eremin@harvard.edu (K.E.) \\ 2 Center for Nanoscale Systems, Harvard University, 11 Oxford Street, Cambridge, MA 02138, USA; \\ amcclelland@cns.fas.harvard.edu (A.M.); aakey@fas.harvard.edu (A.A.) \\ * Correspondence: georgina_rayner@harvard.edu
}

Citation: Rayner, G.; Costello, S.D.; McClelland, A.; Akey, A.; Eremin, K. Preliminary Investigations into the Alteration of Cadmium Orange Restoration Paint on an Ancient Greek Terracotta Krater. Heritage 2021, 4, 1497-1510. https://doi.org/ 10.3390/heritage4030082

Academic Editor: João Pedro Veiga

Received: 28 June 2021

Accepted: 28 July 2021

Published: 29 July 2021

Publisher's Note: MDPI stays neutral with regard to jurisdictional claims in published maps and institutional affiliations.

Copyright: (c) 2021 by the authors. Licensee MDPI, Basel, Switzerland. This article is an open access article distributed under the terms and conditions of the Creative Commons Attribution (CC BY) license (https:// creativecommons.org/licenses/by/ $4.0 /)$.

\begin{abstract}
In preparation for exhibition, an ancient Greek terracotta krater received treatment which included selective in-painting with cadmium orange (CdSSe). After one year on display the object displayed disfiguring alteration in select areas of restoration. Cross-section analysis of samples taken from the object revealed that alteration only occurred in areas where the paint was in direct contact with darkened and abraded areas of the terracotta surface, in which analysis found the presence of chlorine. The alteration was recreated in mock-ups for more in-depth analysis. Using Raman spectroscopy and scanning electron microscopy with energy-dispersive X-rays (SEM-EDS) it was discovered that selenium-rich structures were forming throughout the paint films. The observed alteration is the result of degradation of the CdSSe pigment which occurs in the presence of chlorine and light. This research highlights the need for careful selection of restoration materials when dealing with objects suspected to contain residual chloride ions if desalination cannot be undertaken.
\end{abstract}

Keywords: alteration; cadmium orange; chlorine; selenium; terracotta

\section{Introduction}

The Harvard Art Museums Bell Krater: Torch Race (1960.344, dated c. 430-420 BCE, Figure 1a) was one of several Greek terracotta artefacts which received treatment in preparation for display in 2014. After one year of display the cadmium orange restoration paint on the krater had altered in color in some areas from orange to grey (Figure 1b,c). In comparison, other objects displayed in the same case also in-painted with the same paint showed no sign of alteration. The appearance was deemed unacceptable and re-treatment was required. To appropriately re-treat the krater an understanding of the cause of the alteration was essential and began with understanding the treatment history of the object.

There is no record of any conservation work performed on the krater before its bequest to the museum, however, the object had been re-assembled in the past and this treatment resulted in misplaced joins, abraded surfaces and noticeable over-paint. During a 2004 loan, an efflorescence was observed on the object. The efflorescence was analyzed by SEM-EDS and found to contain calcium and chlorine. FTIR analysis was also performed but the mineral could not be identified with the available spectral databases at that time.

When the spectrum was revisited in the early stages of this investigation, the expansion of the Infrared and Raman Users Group (IRUG) spectral database [1] led to the identification of calclacite $\left(\mathrm{Ca}\left(\mathrm{CH}_{3} \mathrm{COO}\right) \mathrm{Cl} .5 \mathrm{H}_{2} \mathrm{O}\right)$, a calcium chlorine acetate salt (see Figure 5 later). The formation of calclacite has previously been attributed to archaeological ceramics that have residual chlorides from burial or treatment with hydrochloric acid and have been stored in wooden cases [2]. Hydrochloric acid, along with other acids such as acetic or nitric, were used in the past to remove burial accretions [3]. For hydrochloric acid, if not completely removed from the object by rinsing, residual chlorine salts can remain and can react with the acid vapors from the wood resulting in the efflorescence. Based on the 
identification of the efflorescence, the assumption was made that the object underwent incomplete treatment with hydrochloric acid to remove burial accretions at some point in the past.

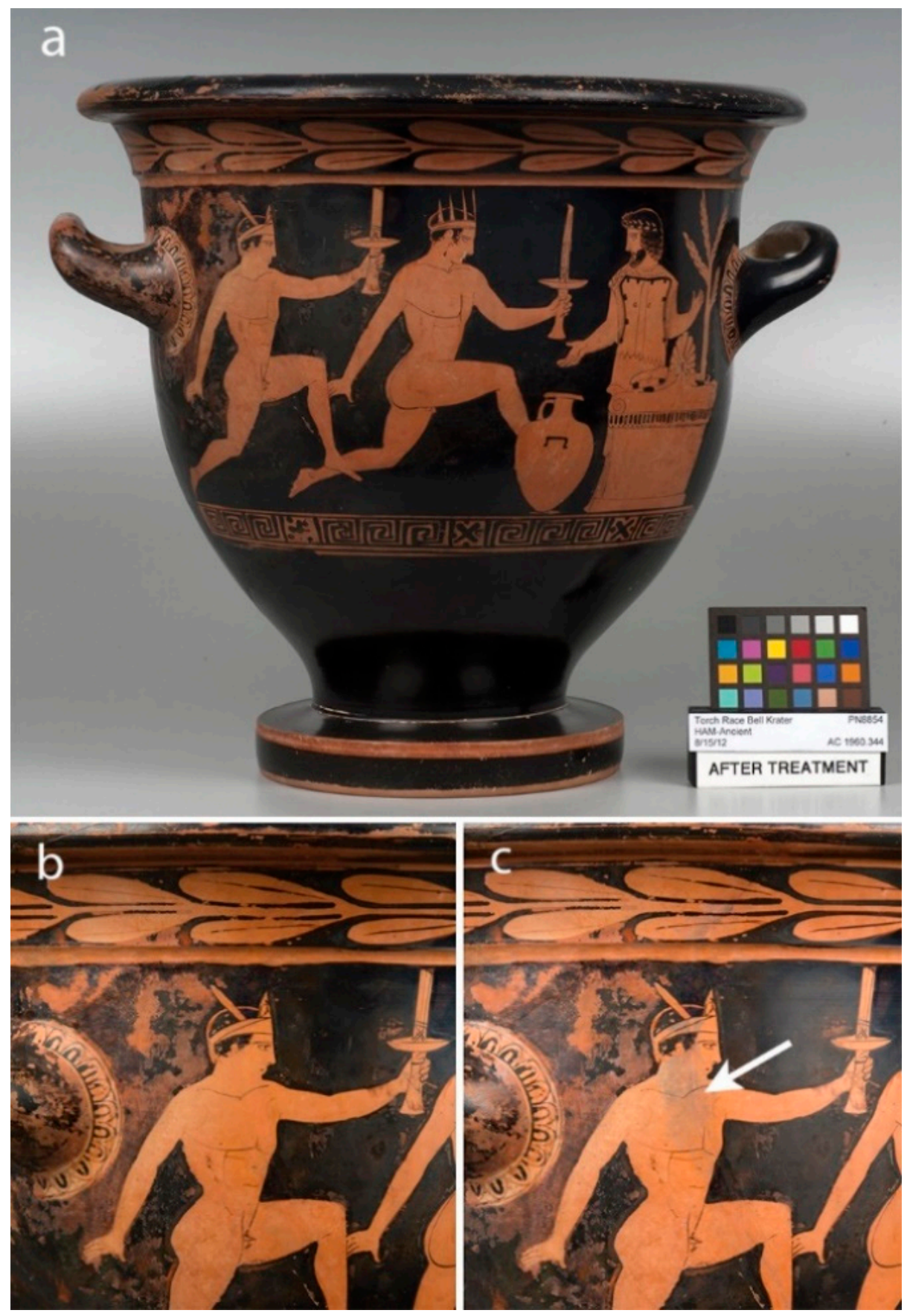

Figure 1. (a) Bell Krater: Torch Race, in the Manner of the Peleus Painter (c. 430-420 BCE, 1960.344) after conservation treatment in 2014. Harvard Art Museums/Straus Center for Conservation and Technical studies, bequest of David Moore Robinson. (b) Inset of male figure after conservation treatment in 2014. (c) Inset of male figure showing alteration of the restoration paint (highlighted by the white arrow) after one year of display.

Desalination was considered during the 2014 treatment of the object but was eventually deemed an unnecessarily risky treatment as restoration joins were considered stable and storage in a controlled environment had prevented the formation of any further efflorescence [4]. Instead, treatment of the object focused on aesthetic work. Disfiguring paint 
was removed, restoration fills levelled, and break lines were filled and sealed with acrylic materials, followed by in-painting. Cadmium orange acrylic paint (Golden Heavy Body Artist Acrylics in C.P. Cadmium Orange), containing CdSSe, was chosen for in-painting due to its ability to lighten the darkened, abraded areas of the terracotta. Titan Buff acrylic paint (Golden Heavy Body Artist Acrylics in Titan Buff), containing titanium white ( $\left.\mathrm{TiO}_{2}\right)$, was added as required to adjust the tone. Full details of the materials used for the treatment may be found in a separate publication [4].

Cadmium pigments offer a broad range of colors from light yellow to deep red. Cadmium yellow is composed of cadmium sulfide (CdS) and the incorporation of Se in increasing amounts changes the color from yellow through orange to red. The alteration of cadmium yellow has been reported in paintings by Henri Matisse [5-9], Edvard Munch [9-12], Vincent Van Gogh [13,14], Pablo Picasso [13,15] and others [13,16-18], all dating from the late 19th-early 20th century, before the stability of pigment was improved [16]. Alteration in areas identified as cadmium sulfide presents itself as either lightening or darkening of the once vibrant pigment.

Researchers have utilized a multitude of analytical tools, and most recently, synchrotronbased radiation techniques, to probe the degradation of the pigment. The observed alteration has been determined to be the result of degradation of the cadmium sulfide pigment through a photo-oxidation process. In the initial stages of the process cadmium sulfate is formed $\left(\mathrm{CdSO}_{4} \cdot \mathrm{xH}_{2} \mathrm{O}\right)$ which then converts to cadmium carbonate $\left(\mathrm{CdCO}_{3}\right)$ and cadmium oxalate (formed from the breakdown of organic components such as binding media [14], $\left.\mathrm{CdC}_{2} \mathrm{O}_{4}\right)$. The formation of these white compounds contributes to the observed lightening of the pigment. The formation of cadmium oxide $(\mathrm{CdO})$, a brown compound, has been associated with darkening [13].

The alteration of cadmium orange (CdSSe) in an artist's work has not previously been identified, however, in the field of semiconductor chemistry, the photo-oxidation of cadmium selenide (CdSe), has been observed. Studies determined that during irradiation of CdSe in the presence of oxygen, photo-oxidation occurs producing cadmium oxide $(\mathrm{CdO})$ and selenium dioxide $\left(\mathrm{SeO}_{2}\right)[19,20]$.

Whilst the degradation of artist materials is not unexpected, in any museum, restoration work performed by conservators is expected to last many decades. Increasing access to technical analysis within museum communities has made it easier for appropriate materials to be chosen and those found not to be suitable, such as fugitive colors, can be avoided. In the unlikely event that restoration materials fail quickly, such as in the case presented here, unusual circumstances are likely involved. The theory developed that the krater had received incomplete treatment with hydrochloric acid in the past warranted further investigation in order to determine if this was the cause of the paint alteration and to inform how to proceed with re-treatment.

\section{Materials and Methods}

\subsection{Samples from the Krater}

Small samples were taken from the krater from areas of restoration with and without alteration and prepared as cross-sections allowing for the stratigraphy of the layers to be observed and analyzed by SEM-EDS. Additional small fragments of the paint film from degraded areas were collected for analysis by Fourier transform infrared (FTIR) spectroscopy, Raman spectroscopy, pyrolysis-Gas Chromatography Mass Spectrometry (pyrolysis-GCMS) and Scanning Electron Microscopy with Energy-Dispersive X-rays (SEM-EDS).

\subsection{Samples of Paint Used for the Conservation Treatment}

Paint used for the conservation treatment, Golden Heavy Body Artist Acrylics in C.P. Cadmium Orange and Titan Buff, were prepared as paint outs on glass microscope slides. The paint films were analyzed by X-ray Fluorescence (XRF) spectroscopy, FTIR, Raman and pyrolysis-GCMS. 


\subsection{Mock-Ups}

Pieces of modern terracotta were acidified by covering with $6 \mathrm{~N}$ hydrochloric acid $(\mathrm{HCl})$ and allowed to dry at least overnight before painting. Each piece was painted with a swatch of cadmium orange and cadmium orange mixed with Titan Buff, mimicking the mixing of the paint in the conservation treatment. Non-acidified pieces of terracotta were prepared for direct comparison to the acidified pieces. The mock-up pairs were used for experiments to recreate the formation of the calclacite efflorescence and to investigate the role of light in the alteration of the cadmium orange paint layer. A final mock-up treated with $1 \mathrm{~N} \mathrm{HCl}$ was also produced to compare with the mock-ups treated with $6 \mathrm{~N}$ $\mathrm{HCl}$. The mock-ups were sampled as needed for preparation as cross-sections, as well as analysis by FTIR, pyrolysis-GCMS and SEM-EDS. Raman analysis was performed directly on the mock-ups.

\subsection{Experimental Methods}

\subsubsection{Cross-Section Preparation}

Samples for cross-section analysis were embedded in Bio-Plastic liquid polyester casting resin (Ward's Natural Science). Sections were ground to exposure using a Buehler Handimet 2 roll grinder with Carbimet abrasive paper rolls ranging in grit from 240-600. Samples were then polished using a Buehler Metaserv 2000 polisher with $6 \mu \mathrm{m}$ and $1 \mu \mathrm{m}$ Buehler MetaDi Monocrystalline Diamond Suspension.

\subsubsection{Optical Microscopy}

Cross-sections and paint swatches on the mock-ups were observed using a Zeiss Axio Imager.M2m upright microscope equipped with four objectives $(5 x, 10 x, 20 x$ and 50x) and a Zeiss Axiocam 512 Color digital camera. Images were captured using the Zeiss Zen 2.6 (blue edition) software. Visible light conditions utilized a halogen lamp and an EPI-polarization filter cube. Ultraviolet (UV) conditions utilized a mercury vapor lamp and a FITC filter cube (excitation BP450-490, beam splitter FT 510 and emission LP515).

\subsubsection{Fourier Transform Infrared (FTIR) Spectroscopy}

FTIR in transmission mode was performed using a Bruker Vertex 70 infrared bench spectrometer coupled to a Bruker Hyperion 3000 infrared microscope. Samples were compressed on to a diamond cell with a stainless-steel roller prior to analysis. Spectra were recorded between 4000 and $600 \mathrm{~cm}^{-1}$ at $4 \mathrm{~cm}^{-1}$ spectral resolution and 32 scans per spectrum. The collected spectra were compared to in-house and published databases.

\subsubsection{Raman Spectroscopy}

Two different systems were used during this study. Analysis of the fresh and degraded paint films were conducted using a Bruker Optics Senterra dispersive Raman microscope with an Olympus BX51M microscope. The $633 \mathrm{~nm}$ laser was used at $5 \mathrm{~mW}$ power with an integration time of either 5 or 10 and 10 co-additions.

Raman measurements of the dark needle-like structures formed in the altered paints were conducted on a Horiba XploRA One confocal Raman microscope with an Olympus LMPLFLN-BD 50x, NA 0.5, long working distance objective and $0.05 \mathrm{~mW}$ of $785 \mathrm{~nm}$ excitation light. A 1200 blaze grating was used. The detector was a $1024 \times 256$ scientific CCD that was thermoelectrically cooled to $-70^{\circ} \mathrm{C}$. Two $90 \mathrm{~s}$ acquisitions were averaged together. Horiba's "Denoiser" smoothing algorithm was applied to the data. A polynomial baseline was fit to the data and subtracted. Spectra were compared with in-house and published databases.

\subsubsection{Pyrolysis-Gas Chromatography Mass Spectrometry (Pyrolysis-GCMS)}

Pyrolysis-GCMS analyses were performed using a CDS pyroprobe 5000 (platinum coil) interfaced to an Agilent Technologies 7890B GC system coupled with an Agilent Technologies 5977A MSD. The samples were placed in the center of a quartz tube. Pyrolysis 
was conducted at $600{ }^{\circ} \mathrm{C}$ for ten seconds. The samples were directed onto the column (HP-5ms Ultra Inert column, $30 \mathrm{~m} \times 25 \mu \mathrm{m} \times 0.25 \mu \mathrm{m}$ ) by helium gas in a 20:1 split ratio. The GC oven was set with an initial temperature of $40^{\circ} \mathrm{C}$ for $1 \mathrm{~min}$ prior to increasing in $10{ }^{\circ} \mathrm{C} / \mathrm{min}$ intervals to $300^{\circ} \mathrm{C}$ over a $26 \mathrm{~min}$ period then maintained for $20 \mathrm{~min}$ for a total acquisition time of $47 \mathrm{~min}$.

\subsubsection{X-ray Fluorescence (XRF) Spectrometry}

A Bruker Artax XRF spectrometer with a Silicon Drift Detector (SDD) and a rhodium anode X-ray tube was used for analysis. The primary X-ray beam is collimated to give a spot size of $0.65 \mathrm{~mm}$. Spectra were acquired for $100 \mathrm{~s}$ live time at $50 \mathrm{kV}$ and $600 \mu \mathrm{A}$. A helium flux was used to increase the detection efficiency for light elements (atomic number of potassium and lower).

\subsubsection{Scanning Electron Microscopy with Energy-Dispersive X-ray Spectrometry} (SEM-EDS)

Two different systems were used during this study. Initial analysis of the crosssections was conducted using a JEOL JSM-6460LV SEM with an Oxford Instruments $80 \mathrm{~mm}^{2} \mathrm{X}$-MaxN X-ray spectrometer running the Oxford INCA software. The SEM was operated in low vacuum mode at a chamber pressure of $35 \mathrm{~Pa}$, with an operating voltage of $20 \mathrm{kV}$, beam current circa $1 \mathrm{nA}$ and working distance of $10 \mathrm{~mm}$. The cross-sections were not coated prior to analysis.

More detailed analysis including mapping of the cross-sections and paint films were collected using an FEI Helios 660 Dual-Beam SEM/FIB equipped with an EDAX Octane Plus EDS system, with EDAX TEAM brand acquisition and mapping software. Samples were prepared for imaging by carbon-coating with a layer of amorphous carbon of between 50-100 nm thickness, for electrical discharge purposes. Images were collected using an accelerating voltage of $3 \mathrm{kV}$, beam current of $3.2 \mathrm{nA}$. EDS maps were acquired with an accelerating voltage of $15 \mathrm{kV}$ and a beam current of $13 \mathrm{nA}$.

\section{Results and Discussion}

\subsection{Analysis of Cross-Sections from the Krater}

The discoloration of the paint was exclusively observed to occur in areas where the restoration paint was in contact with abraded areas around break lines in the ceramic. No alteration was observed when the paint was applied over the acrylic fills from the 2014 treatment. In Figure 2a, the terracotta of the krater is present in a cross-section prepared from an area where the paint altered, observable as a very uniform substrate layer. In Figure 2b, a cross-section prepared from an area where the paint did not alter, the paint is applied to a mixture of restoration materials instead of terracotta. Clearly different from the original terracotta (Figure 2a), this substrate is consistent with the presence of fill materials applied during the 2014 treatment and from the earlier, undated treatment.

The paint layer, measuring between 3-5 $\mu \mathrm{m}$, appears almost completely white in the altered cross-section with only a few remaining colored particles. The paint layer is difficult to see in the unaltered cross-section, however with ultraviolet (UV) illumination a distinct green fluorescence from the paint layer is observable.

Analysis using SEM-EDS (Figure 3) confirmed the presence of chlorine $(\mathrm{Cl})$ in the altered paint layer and in the terracotta (not shown in Figure 3). No $\mathrm{Cl}$ was observed in any of the layers in cross-sections prepared from the unaltered paint. This observation, combined with the identification of calclacite from the 2004 efflorescence, suggested that the alteration may be caused by an interaction between the cadmium orange restoration paint and residual chloride ions in the terracotta. 


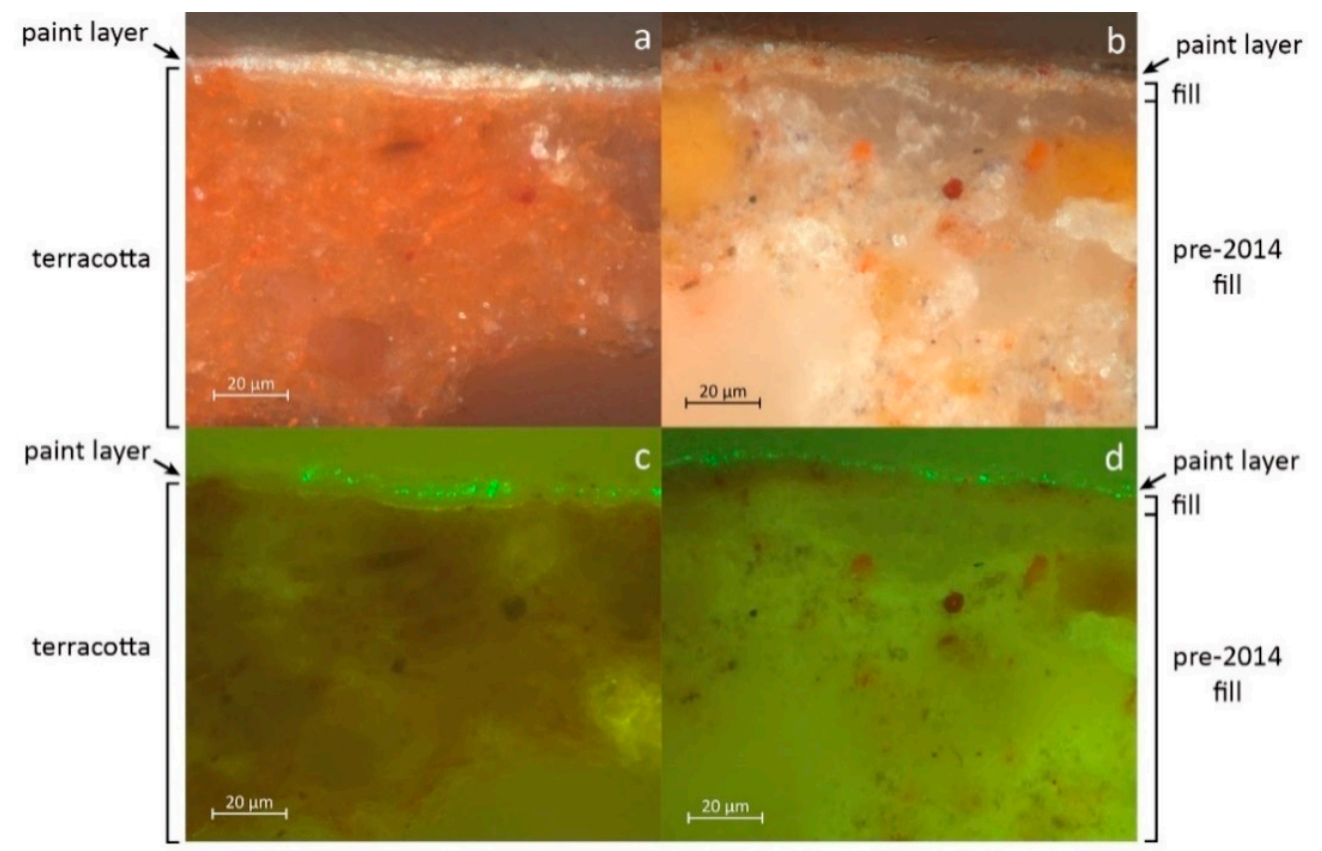

Figure 2. Microscope images of cross-section samples taken from the krater. (a) altered paint sampled from the male figure (pictured in Figure 1c) in which the restoration paint sits directly on top of the terracotta surface. (b) unaltered paint sampled from an area in which the paint was not in contact with the terracotta due to the presence of fill materials. (c,d) represent the same areas depicted in (a,b) taken with UV illumination (FITC filter cube).

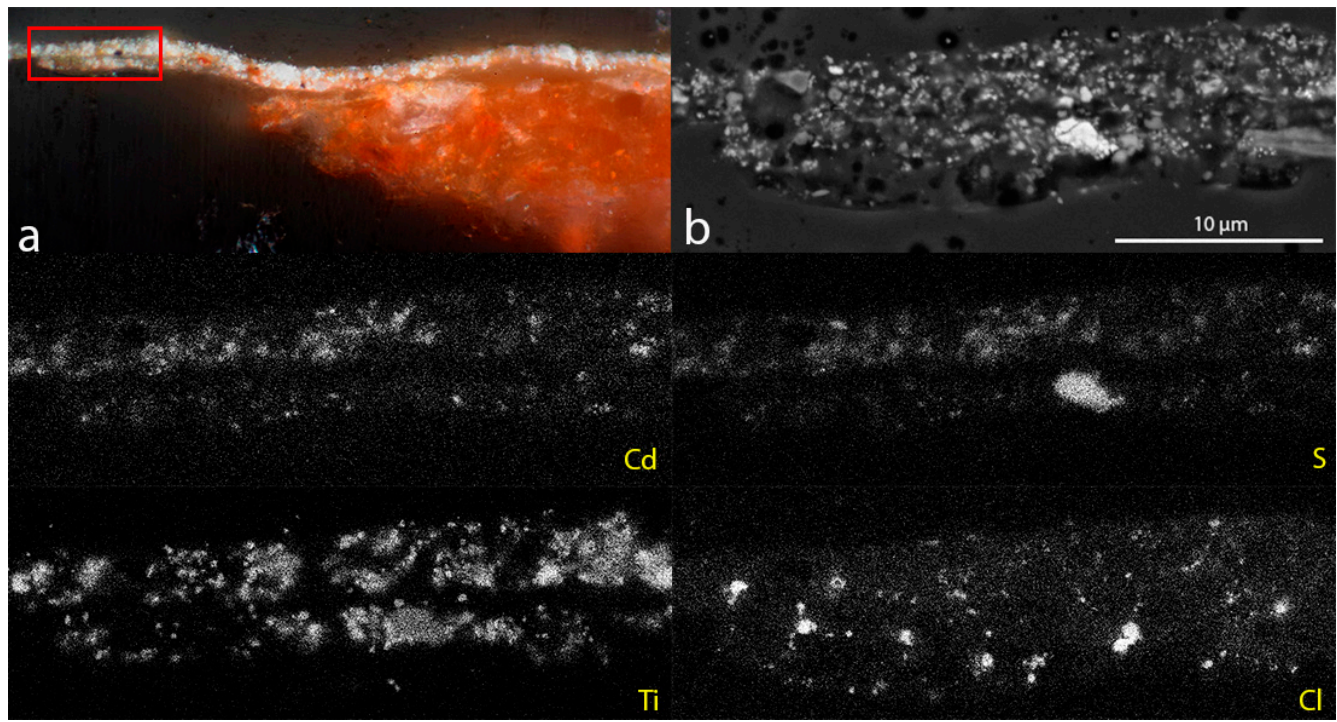

Figure 3. (a) Microscope image of cross-section prepared from a sample taken from an area of alteration on the krater. (b) SEM backscattered electron image of the altered paint film which has been highlighted in (a) by the red rectangle with EDS maps below showing $\mathrm{Cd}, \mathrm{S}$, Ti and $\mathrm{Cl}$ channels.

\subsection{Characterization of the Fresh Paint}

The paint film prepared from Golden Heavy Body Artist Acrylics in C.P. Cadmium Orange is uniformly orange in color with no obvious inclusions. Elemental analysis by XRF of the cadmium orange paint confirmed the presence of cadmium (Cd), sulfur (S) and selenium (Se), consistent with the cadmium orange pigment. Barium (Ba) and zinc (Zn) were additionally identified in the paint. 
The Raman spectrum of the cadmium orange paint (Figure 4a) contains bands assigned to the longitudinal optical (LO) phonon and overtone (2LO) of CdS at 296 and $595 \mathrm{~cm}^{-1}$, respectively. The LO phonon for CdSe is typically observed at around $200 \mathrm{~cm}^{-1}$ but may shift in wavenumbers based on the pigment composition, and as such may be accounted for by either or both of the peaks at 192 and $214 \mathrm{~cm}^{-1}$ [21]. The presence of barium sulfate, identifiable in Figure 4a by the peak at $988 \mathrm{~cm}^{-1}$ representing the symmetric stretching of the $\mathrm{SO}_{4}$ group, indicates that the paint contains the lithopone version of cadmium orange [16]. The mineral form of zinc could not be identified from analysis, however, the identification of lithopone may suggest the presence of zinc sulfide ( $\mathrm{ZnS}$ ) and the UV fluorescence observed in the paint, discussed below, may be attributed to the presence of zinc oxide $(\mathrm{ZnO})$.

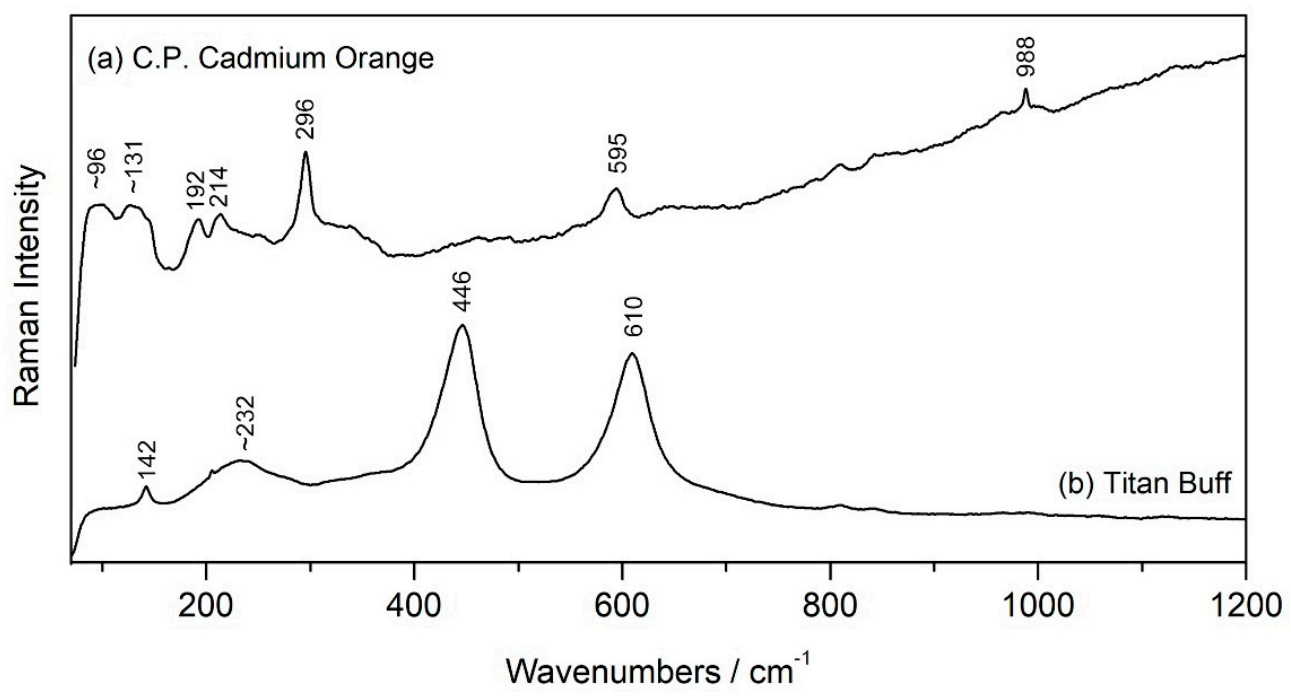

Figure 4. Raman spectra obtained from (a) fresh C.P. Cadmium Orange acrylic paint (Golden Heavy Body Artist Acrylics) and (b) fresh Titan Buff acrylic paint (Golden Heavy Body Artist Acrylics).

The cadmium orange paint has the same distinct green UV fluorescence visible in the cross-section images shown in Figure $2 \mathrm{c}, \mathrm{d}$. The fluorescence occurs from very fine particles distributed evenly throughout the paint matrix. Multiple cadmium orange reference samples and pure barium sulfate displayed no fluorescence under the same UV conditions. A reference sample for lithopone contained a scattering of particles which fluoresced pale yellow, typical of zinc oxide $(\mathrm{ZnO})$. Zinc oxide may be present in lithopone in trace amounts, and whilst the fluorescence of zinc oxide is not a match for the green fluorescence observed in the cadmium orange paint film, it is the only pigment identified to have a fluorescence that may be present. It is speculated that the fluorescence color has altered as a result of the paint preparation, however, further study is required.

The paint film prepared from Golden Heavy Body Artist Acrylics in Titan Buff is off-white in color and includes both red and black inclusions. XRF analysis of the paint film showed the presence of titanium (Ti) and Raman analysis identified the presence of rutile (titanium dioxide, $\mathrm{TiO}_{2}$ ), based on the presence of $\mathrm{B}_{1 \mathrm{~g}}, \mathrm{E}_{\mathrm{g}}$ and $\mathrm{A}_{1 \mathrm{~g}}$ Raman active modes of the of the rutile single crystal at 142, 446 and $610 \mathrm{~cm}^{-1}$, respectively (Figure 4b) [22]. The red and black inclusions were identified as hematite $\left(\mathrm{Fe}_{2} \mathrm{O}_{3}\right)$ and rutile, respectively, with Raman. The identification of rutile in the black inclusions suggests the use of the natural form of the mineral in addition to the white synthetic form used for the bulk of the paint [23].

Importantly, no $\mathrm{Cl}$ was identified in either of the paints, supporting the theory that residual chloride ions in the terracotta are involved in the observed alteration of the paint. FTIR analysis confirmed the presence of an acrylic binder in both the cadmium orange and Titan Buff paints, which was identified to contain a combination of methyl methacrylate, n-butyl acrylate and n-butyl methacrylate by pyrolysis-GCMS. 


\subsection{Mock-Up Study}

Mock-ups were created to allow for more extensive study of the paint alteration as the amount of altered material from the krater was limited. The mock-ups were created in pairs with one terracotta piece acidified using $6 \mathrm{~N}$ hydrochloric acid and the other without. Each mock-up was painted with a swatch of the pure cadmium orange paint and a swatch of the cadmium orange paint mixed with the Titan Buff, mimicking the conservation treatment.

Initial mock-ups were designed to recreate the conditions which are assumed to have contributed to the formation of the efflorescence observed in 2004. One mock-up pair was sealed in a bag with a small volume of acetic acid, approximately $2 \mathrm{~mL}$, to recreate the proposed scenario which caused the formation of the calclacite efflorescence on the krater. White efflorescence formed on the acidified mock-up after three days. The efflorescence was sampled, analyzed by FTIR and identified as calclacite (Figure 5). No efflorescence was observed on the non-acidified mock-up.

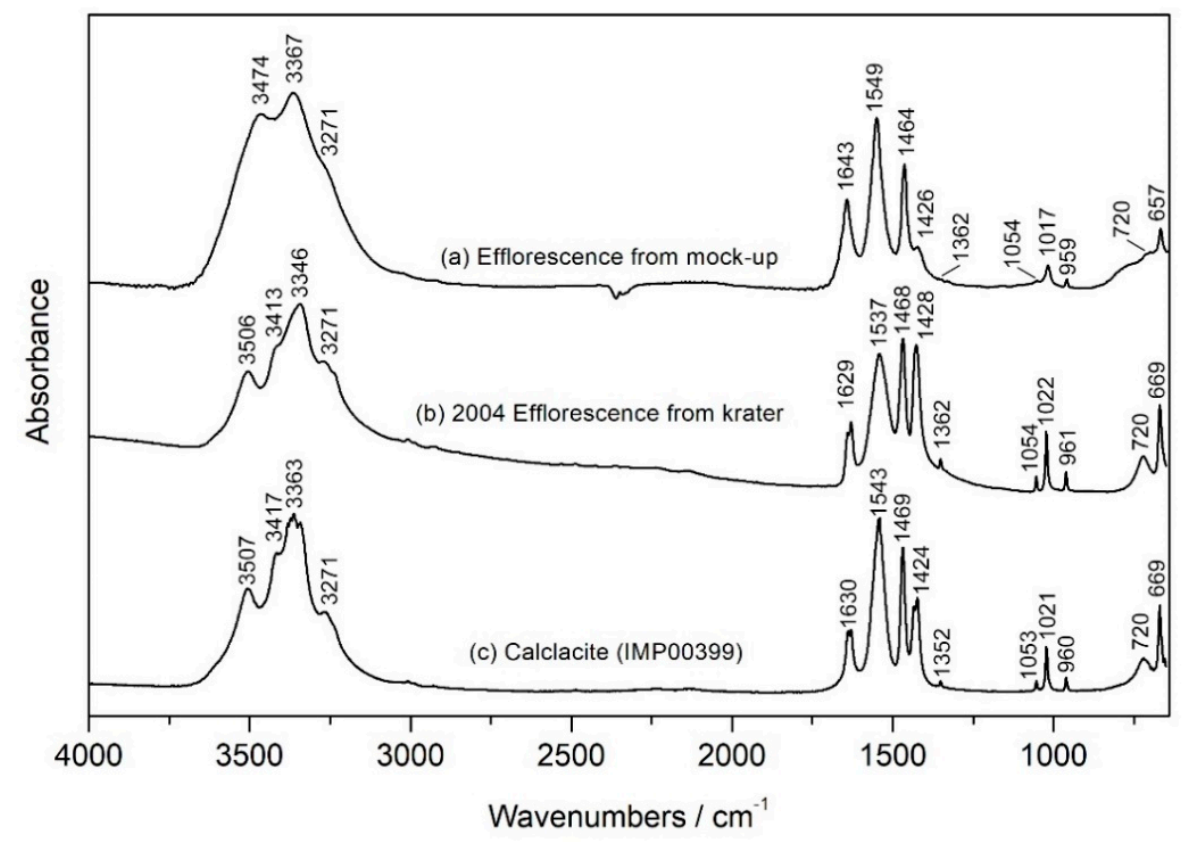

Figure 5. FTIR results for efflorescence formed on (a) a mock-up treated with hydrochloric acid and exposed to acetic acid, compared with (b) the efflorescence that formed on the krater whilst on loan in 2004 and (c) a reference spectrum for calclacite from the IRUG database.

Next, a series of mock-ups were created to study the effects of both chloride ions and light on the alteration of the pigment, aiming to investigate whether display conditions had contributed to the alteration. Mock-up pairs (acidified and non-acidified), were placed in bright natural light (1 and 2), non-direct light ( 3 and 4 ) and in the dark (5 and 6). The mock-ups in direct light received direct natural light through a window which filters out the majority of UV radiation. Those placed in indirect light were sheltered from direct natural light, mimicking the closest scenario to the display conditions of the object. The mock-ups which received no light were kept in a closed draw.

During the first three months of exposure, mock-ups in direct light received approximately $9 \mathrm{~h}$ of natural daylight per day. The amount of light these mock-ups received during daylight hours varied between 207-2624 footcandles, the equivalent of approximately 2140-28,400 Lux, with the measured UV content of the light varying between 5.7-14.4 mW/Lumen (determined using an ELSEC 765 Environmental Monitor). The lower values are associated with overcast, cloudy days and the higher values with bright, sunny days. The amount of light received by the mock-ups in indirect light during the same time frame remained below 10 footcandles (108 Lux) and UV measurements were consistently zero. 
The acidified mock-ups in direct and indirect light (mock-ups 2 and 4, respectively) began to noticeably alter within one month with the cadmium orange darkening to brown and the cadmium orange/Titan Buff mixture changing to grey, matching the observed alteration on the krater. The acidified mock-up placed in the dark (mock-up 6) displayed no visible change after one year and no change was seen on the non-acidified mock-ups at any light level. Figure 6 shows the mock-ups after one year.

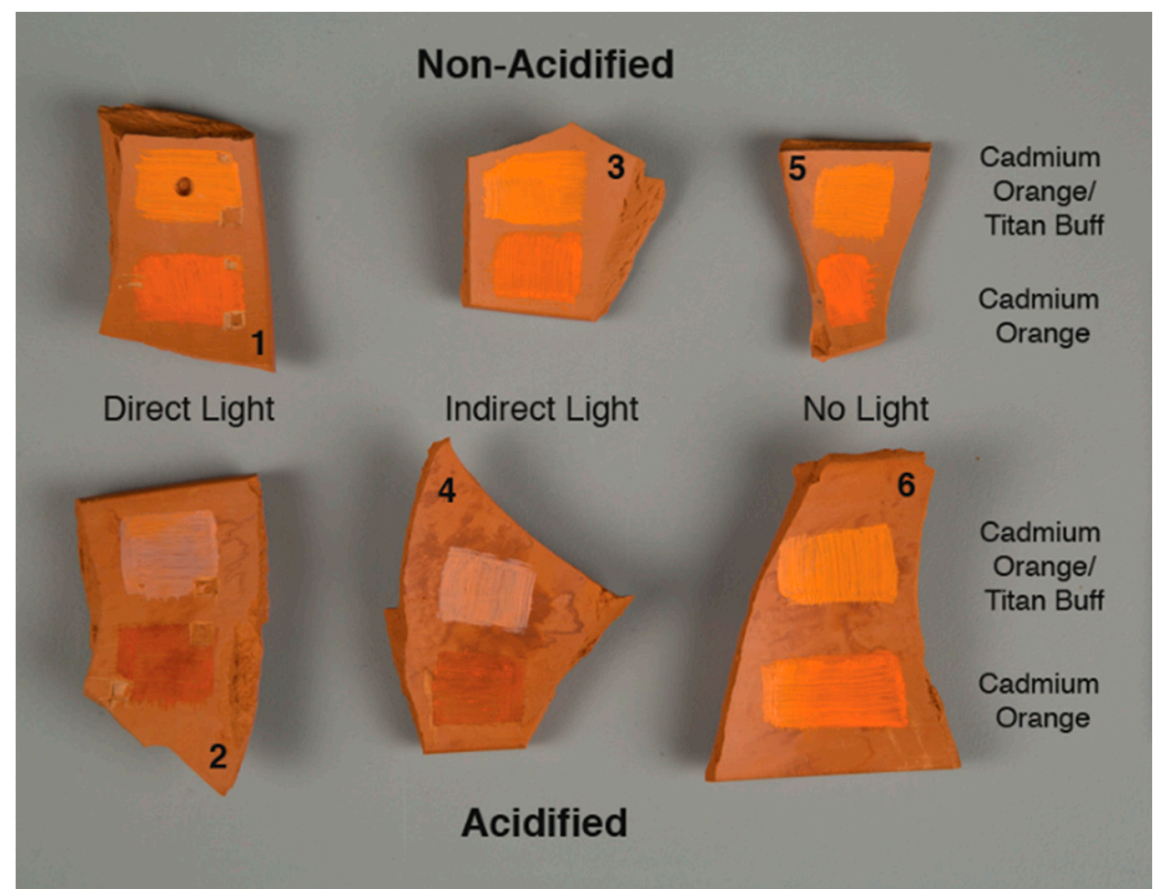

Figure 6. Mock-ups created to investigate the alteration of cadmium orange pictured after one year of exposure to direct light (mock-ups 1 and 2, left), indirect light (mock-ups 3 and 4, center) and no light (mock-ups 5 and 6, right). The pieces in the top row were not acidified prior to painting. Each piece of terracotta is painted with a swatch of cadmium orange/Titan Buff on the top half and cadmium orange on the bottom half.

The mock-ups used for this study were treated with $6 \mathrm{~N}$ hydrochloric acid to produce a quick reaction. A mock-up treated with $1 \mathrm{~N}$ hydrochloric acid was created for comparison with the more harshly acidified samples. The same alteration was observed on the mock-up acidified with $1 \mathrm{~N}$ hydrochloric acid, albeit occurring at a reduced rate in comparison to the $6 \mathrm{~N}$ counterpart taking at least three months for any noticeable alteration to occur.

\subsection{Characterization of the Altered Paint from the Mock-Ups and the Krater}

A greyed appearance on terracotta ceramics in-painted with acrylic paints has been observed before and was attributed to residual solvent retained in the terracotta substrate migrating to the surface carrying lighter pigments with it [24]. This was considered as a possibility, however, other terracotta ceramics treated in the same manner as the krater did not show the same alteration and not all of the mock-ups altered as might be expected if this was the case. The migration of pigments could also not be confirmed from SEM-EDS mapping of the paint films in cross-section, with the elements associated with the paint layers remaining relatively evenly distributed across the paint layer (see Figure 3).

A key observation in the alteration of the paint films on mock-ups 2 and 4 was the formation of dark needle-like structures which are visible only with high magnification in both the cadmium orange paint swatch and the cadmium orange/Titan Buff swatch, the latter shown in Figure 7a. Whilst these needle-like structures formed on both mock-ups, the formation was more extensive in the mock-up exposed to direct light (mock-up 2), suggesting that high light exposure acts as a catalyst for formation but is not required. The 
analysis described here is focused on the cadmium orange/Titan Buff altered paint film on mock-up 4 as it most closely resembles the paint mixture and conditions under which alteration occurred on the krater.

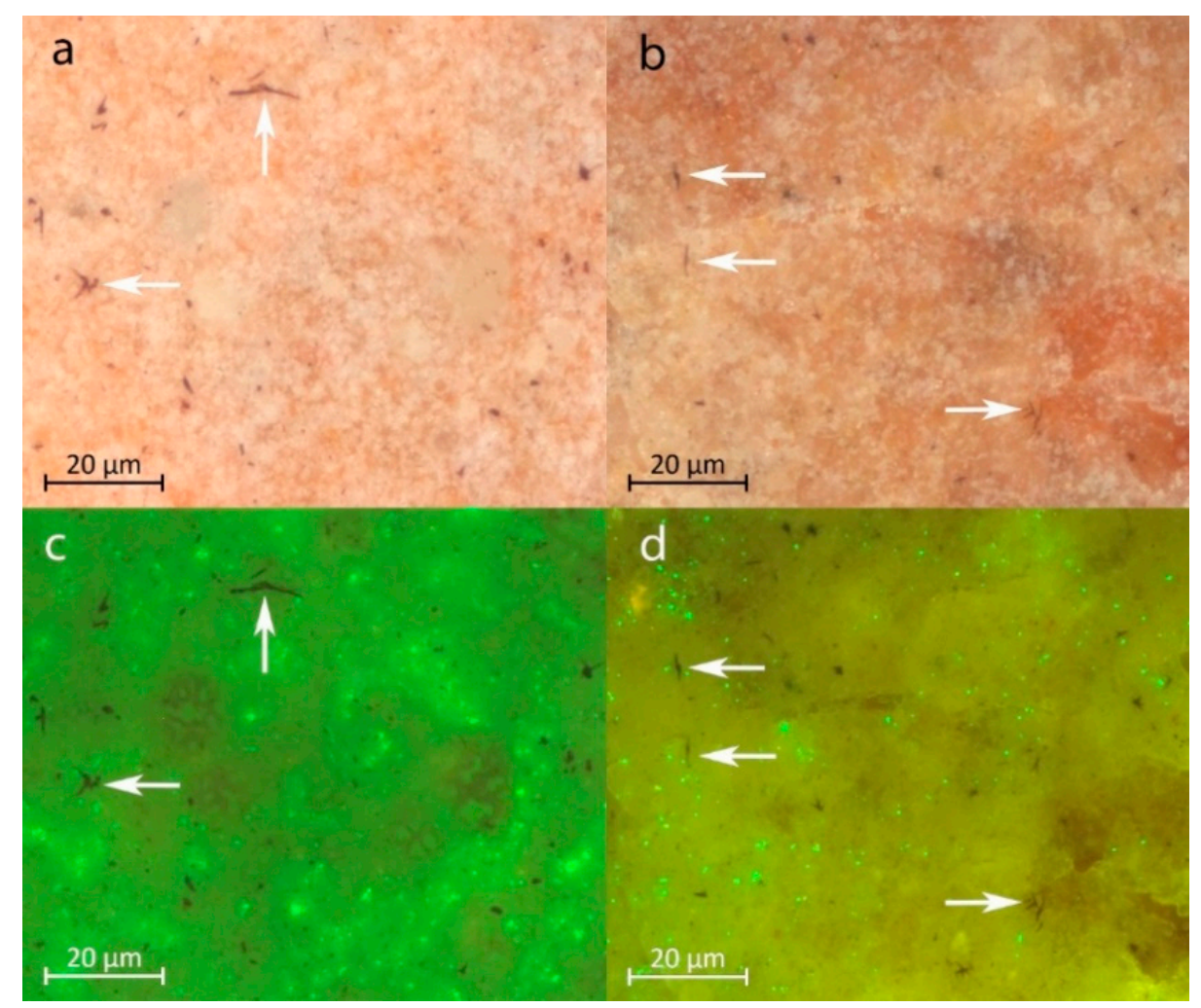

Figure 7. Dark needle-like structures formed in (a) the cadmium orange/Titan Buff paint mixture on mock-up 4 (exposed to indirect light) and (b) the altered paint layer on the krater. (c,d) represent the same areas depicted in $(\mathbf{a}, \mathbf{b})$ taken with UV illumination (FITC filter cube). White arrows have been used to highlight some of the larger needle-like structures.

A sample of the altered paint from the krater was revisited and the same dark needlelike structures were observed (Figure $7 \mathrm{~b}$ ). These structures are a little more difficult to see in the visible and UV image (Figure $7 \mathrm{~b}$ and $\mathrm{d}$, with some structures highlighted by white arrows), due to their small size which is comparable to the dark inclusions present in the Titan Buff paint.

SEM-EDS imaging of the altered paint from mock-up 4 shows that the majority of the dark needle-like structures, which are in the order of $1 / 2 \mu \mathrm{m}$ long, can be seen just underneath the surface of the paint film whilst a few protrude slightly from the surface. SEM-EDS mapping revealed that the structures are rich in Se (Figure 8a). None of the other elements associated with the pigments $(\mathrm{Cd}, \mathrm{S}$ and $\mathrm{Ti})$ or $\mathrm{Cl}$ appear to be associated with the structures. Raman spectra collected from the structures have a unique sharp Raman peak around $234 \mathrm{~cm}^{-1}$ which is a match to a reference spectrum of Se available through the RRUFF ${ }^{\mathrm{TM}}$ project database (R050656, Figure 9) [25]. Comparison with the literature indicates that this Raman band corresponds to the trigonal, polymeric form of Se $\left(t-\mathrm{Se}_{\mathrm{n}}\right)$ [26]. Clusters of dark needle-like structures protruding from the paint surface, similar in size to the Se-rich structures observed in the mock-up paint, were identified in the altered paint taken from the krater with SEM-EDS mapping again revealing that the structures are rich in Se (Figure $8 \mathrm{~b}$ ) and the Raman spectrum matches the reference for Se already discussed (Figure 9). 

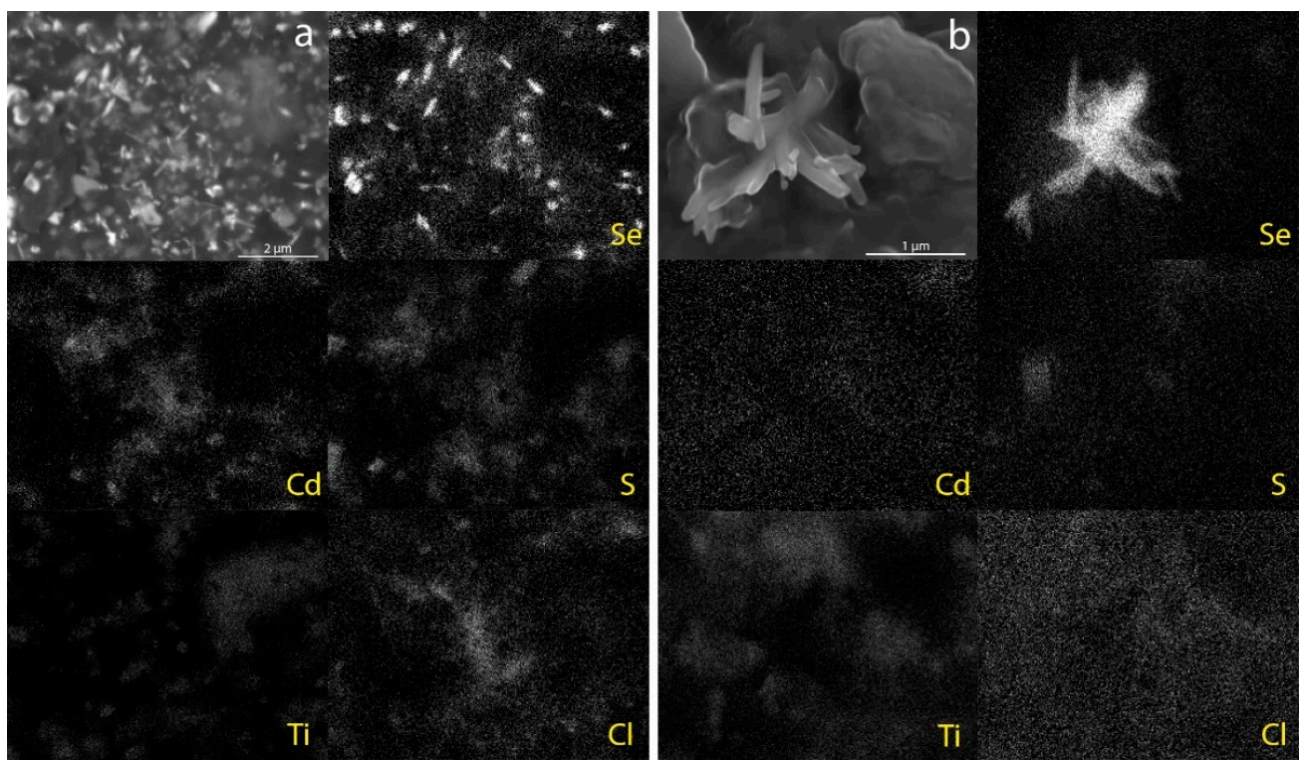

Figure 8. (a) SEM backscattered electron image of surface of mock-up 4 with EDS maps showing Se, $\mathrm{Cd}, \mathrm{S}$, Ti and $\mathrm{Cl}$ channels. (b) SEM backscattered electron image of paint taken from altered region of the Krater, showing a branched structure located at the surface with EDS maps showing Se, Cd, S, Ti and $\mathrm{Cl}$ channels.

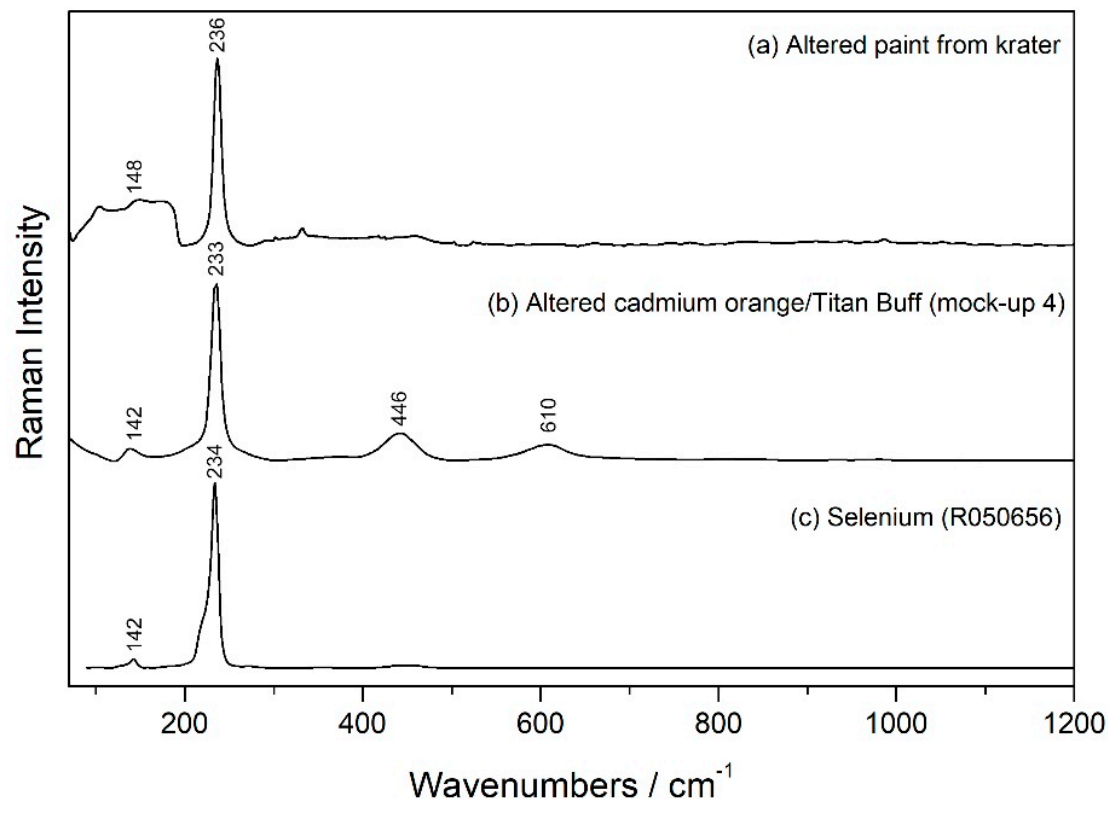

Figure 9. Raman spectra obtained from (a) a dark needle-like structure from the altered paint taken from the krater and (b) a dark needle-like structure within the altered cadmium orange/Titan Buff paint from mock-up 4 compared with (c) a reference spectrum of selenium available through the RRUFF $^{\text {TM }}$ database. The broader peaks visible in spectrum (b) at 446 and $610 \mathrm{~cm}^{-1}$ are associated with the rutile in the Titan Buff paint in the paint matrix surrounding the needle-like structures.

The FTIR spectrum of the altered paint from both the mock-ups and krater remained relatively unchanged in comparison to the spectra of the fresh paint. Whilst the formation of different cadmium compounds (for example $\mathrm{CdC}_{2} \mathrm{O}_{4}, \mathrm{CdCO}_{3}$ ) may be identified in the FTIR spectrum [12,15], the strong signal from the acrylic binder prevented their identification if present. No apparent degradation of the acrylic binder was observed in the pyrolysis-GCMS chromatogram. 
Raman spectra of the paint surrounding the Se-rich structures are shown for the altered paint from the krater, the altered cadmium orange/Titan Buff swatch from mockup 4 and the altered cadmium orange swatch from mock-up 2 in Figure 10. The only recognizable feature from the fresh paint is the presence of rutile in the spectra from the krater and mock-up 4 (Figure 10a,b, respectively). The peaks associated with the cadmium orange pigment (shown in Figure 4a, with peak locations shaded in orange in Figure 10) are absent in all three spectra. Instead, the presence of Se remains visible (highlighted by the red shaded area in Figure 10) and a new peak has formed in the mock-ups at $251 \mathrm{~cm}^{-1}$, noted in Figure 10 by the area shaded blue. This peak remains unidentified, seemingly not associated with any of the previously identified degradation products of cadmium pigments $\left(\mathrm{CdSO}_{4} \cdot \mathrm{xH}_{2} \mathrm{O}, \mathrm{CdCO}_{3}, \mathrm{CdC}_{2} \mathrm{O}_{4}\right.$ or $\left.\mathrm{CdO}\right)$.

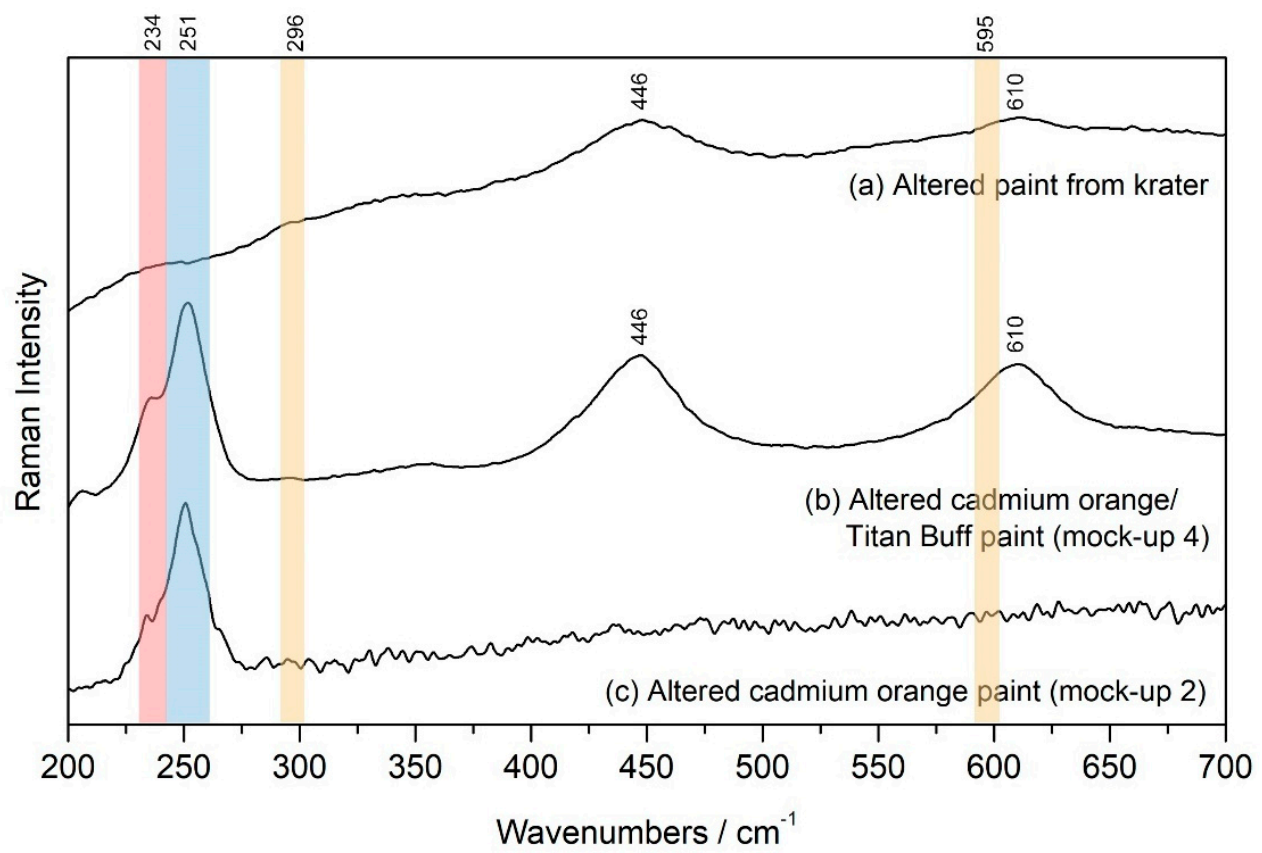

Figure 10. Detailed region from $200-700 \mathrm{~cm}^{-1}$ of the Raman spectra obtained from the altered paint surrounding the Se-rich structures from (a) the krater, (b) the cadmium orange/Titan Buff paint from mock-up 4 and (c) the cadmium orange paint from mock-up 2. The orange shaded areas indicate where the peaks associated with the cadmium orange pigment were located in this region (296 and $595 \mathrm{~cm}^{-1}$, now absent). The red shaded area indicates the peak associated with selenium at $234 \mathrm{~cm}^{-1}$ and the blue shaded area highlights the new peak observed at $251 \mathrm{~cm}^{-1}$. The broad peaks centered at 446 and $610 \mathrm{~cm}^{-1}$ are associated with rutile from the Titan Buff paint.

\section{Conclusions}

Using complementary analytical techniques it was determined that the alteration observed for the restoration paint applied to the krater is the result of degradation of the cadmium orange (CdSSe) pigment. This conclusion is supported by the identification of selenium-rich needle-like structures of the trigonal $\mathrm{Se}_{\mathrm{n}}$ form within the paint film after alteration occurs, as observed in both the altered paint from the krater and in the mock-ups created to study the cause of the alteration. Based on the behavior of the restoration paint on the ancient Greek krater and on the mock-ups, alteration occurs only in areas of acidified ceramic and in the presence of light. It is hypothesized that the residual chloride ions in the terracotta, resulting from either burial or incomplete treatment with $\mathrm{HCl}$ to remove burial accretions, and light exposure act as catalysts for the observed alteration. This is consistent with observations in the literature in which mobile chloride ions have been associated with promoting the oxidation of cadmium sulfide [12] as well as making the pigment more sensitive to photo-oxidation $[5,27]$. 
Based on previous research it was anticipated that cadmium would form white (e.g., $\left.\mathrm{CdSO}_{4}, \mathrm{CdCO}_{3}\right)$ or brown $(\mathrm{CdO})$ compounds, however, no cadmium-containing compounds were identifiable during this preliminary study. This research will hopefully be extended in the future to fully deduce the cadmium-containing degradation products and further investigate the role of acidity / $\mathrm{pH}$ in the alteration. Together, this will allow for a better understanding of the full mechanistic process in which the degradation of cadmium orange occurs.

For the re-treatment of the krater, the altered paint film was removed and noncadmium containing pigments (Golden Fluid Acrylics cadmium red and yellow) used for in-painting after mock-ups determined them to be stable under the conditions tested during this study [4]. This same treatment will be used in the future for other ceramics known, or suspected, to have been treated with hydrochloric acid.

Author Contributions: Conceptualization, S.D.C., K.E. and G.R.; methodology, S.D.C., K.E. and G.R.; formal analysis, G.R., K.E., A.M. and A.A.; investigation, G.R., K.E., A.M. and A.A.; resources, S.D.C.; writing—original draft preparation, G.R.; writing—review and editing, G.R., S.D.C., K.E., A.M. and A.A.; visualization, G.R.; supervision, K.E. All authors have read and agreed to the published version of the manuscript.

Funding: This work was performed in part at the Center for Nanoscale Systems (CNS), a member of the National Nanotechnology Coordinated Infrastructure Network (NNCI), which is supported by the National Science Foundation under NSF award no. ECCS-2025158. CNS is part of Harvard University.

Institutional Review Board Statement: Not applicable.

Informed Consent Statement: Not applicable.

Data Availability Statement: The data presented in this study is available on request from the corresponding author. Publicly available datasets were used for reference material in this study. This data can be found here: http:/ / www.irug.org/search-spectral-database, accessed on 9 June 2021; https:/ / rruff.info, accessed on 9 June 2021.

Conflicts of Interest: The authors declare no conflict of interest. The funders had no role in the design of the study; in the collection, analyses, or interpretation of data; in the writing of the manuscript, or in the decision to publish the results.

\section{References}

1. Price, B.A.; Pretzel, B.; Quillen Lomax, S. (Eds.) Infrared and Raman Users Group Spectral Database. Available online: www.irug.org (accessed on 9 June 2021).

2. Fitzhugh, E.W.; Gettens, R.J. Calclacite and Other Efflorescent Salts on Objects Stored in Wooden Museums Cases. In Science and Archaeology; Brill, R.H., Ed.; MIT Press: Cambridge, MA, USA; London, UK, 1971; pp. 91-101.

3. Johnson, J.S.; Erickson, H.M.; Iceland, H. Identification of Chemical and Physical Change during acid Cleaning of Ceramics. MRS Proc. 1995, 352, 831-837. [CrossRef]

4. Costello, S.D.; Rayner, G.; Eremin, K. The degradation of cadmium orange restoration paint on an ancient Greek terracotta vase. In Proceedings of the ICOM-CC 18th Triennial Conference Preprints, Copenhagen, Denmark, 4-8 September 2017.

5. Mass, J.L.; Opila, R.; Buckley, B.; Cotte, M.; Church, J.; Mehta, A. The photodegradation of cadmium yellow paints in Henri Matisse's Le Bonheur de vivre (1905-1906). Appl. Phys. A 2012, 111, 59-68. [CrossRef]

6. Mass, J.; Sedlmair, J.; Patterson, C.; Carson, D.; Buckley, B.; Hirschmugl, C. SR-FTIR imaging of the altered cadmium sulfide yellow paints in Henri Matisse's Le Bonheur de vivre (1905-6)—Examination of visually distinct degradation regions. Analyst 2013, 138, 6032-6043. [CrossRef] [PubMed]

7. Pouyet, E.; Cotte, M.; Fayard, B.; Salome, M.; Meirer, F.; Mehta, A.; Uffelman, E.S.; Hull, A.; Vanmeert, F.; Kieffer, J.; et al. 2D X-ray and FTIR micro-analysis of the degradation of cadmium yellow pigment in paintings of Henri Matisse. Appl. Phys. A 2015, 121, 967-980. [CrossRef]

8. Voras, Z.E.; Deghetaldi, K.; Wiggins, M.B.; Buckley, B.; Baade, B.; Mass, J.L.; Beebe, T.P. ToF-SIMS imaging of molecular-level alteration mechanisms in Le Bonheur de vivre by Henri Matisse. Appl. Phys. A 2015, 121, 1015-1030. [CrossRef] [PubMed]

9. Mass, J.L.; Uffelman, E.; Buckley, B.; Grimstad, I.; Vila, A.; Delaney, J.; Wadum, J.; Andrews, V.; Burns, L.; Florescu, S.; et al. Portable X-ray Fluorescence and Infrared Fluorescence Imaging Studies of Cadmium Yellow Alteration in Paintings by Edvard Munch and Henri Matisse in Oslo, Copenhagen, and San Francisco. In Smithsonian Contributions to Museum Conservation No. 5, The Noninvasive Analysis of Pianted Surfaces: Scientific Impact and Conservation Practice; Doherty, T., Nevin, A., Eds.; Smithsonian Institution Scholarly Press: Washington, DC, USA, 2016; pp. 53-64. 
10. Plahter, U.; Topalova-Casadiego, B. The Scream by Edvard Munch: Painting techniques and colouring materials. In The National Gallery Technical Bulletin 30th Anniversary Conference Postprints; Spring: London, UK, 2011; pp. 244-252.

11. Levin, B.D.; Nguyen, K.X.; Holtz, M.E.; Wiggins, M.B.; Thomas, M.G.; Tveit, E.S.; Mass, J.L.; Opila, R.; Beebe, T.; Muller, D.A. Detection of CdS Nanoparticles and Implications for Cadmium Yellow Paint Degradation in Edvard Munch's The Scream (c. 1910, Munch Museum). Microsc. Microanal. 2017, 23, 1910-1911. [CrossRef]

12. Monico, L.; Cartechini, L.; Rosi, F.; Chieli, A.; Grazia, C.; De Meyer, S.; Nuyts, G.; Vanmeert, F.; Janssens, K.; Cotte, M.; et al. Probing the chemistry of CdS paints in The Scream by in situ noninvasive spectroscopies and synchrotron radiation $\mathrm{X}$-ray techniques. Sci. Adv. 2020, 6, eaay3514. [CrossRef] [PubMed]

13. Leone, B.; Burnstock, A.; Jones, C.; Hallebeek, P.; Boon, J.; Keune, K. The deterioration of cadmium sulphide yellow artists' pigments. In Proceedings of the ICOM-CC 14th Triennial Conference Preprints, The Hague, The Netherlands, 12-16 September 2005; Volume 2.

14. Van Der Snickt, G.; Janssens, K.; Dik, J.; De Nolf, W.; Vanmeert, F.; Jaroszewicz, J.; Cotte, M.; Falkenberg, G.; Van Der Loeff, L. Combined use of Synchrotron Radiation Based Micro-X-ray Fluorescence, Micro-X-ray Diffraction, Micro-X-ray Absorption Near-Edge, and Micro-Fourier Transform Infrared Spectroscopies for Revealing an Alternative Degradation Pathway of the Pigment Cadmium Yellow in a Painting by Van Gogh. Anal. Chem. 2012, 84, 10221-10228. [CrossRef] [PubMed]

15. Comelli, D.; MacLennan, D.; Ghirardello, M.; Phenix, A.; Patterson, C.S.; Khanjian, H.; Gross, M.; Valentini, G.; Trentelman, K.; Nevin, A. Degradation of Cadmium Yellow Paint: New Evidence from Photoluminescence Studies of Trap States in Picasso's Femme (Époque des “Demoiselles d'Avignon"). Anal. Chem. 2019, 91, 3421-3428. [CrossRef] [PubMed]

16. Fielder, I.; Bayard, M. Cadmium Yellows, Oranges and Reds. In Artists' Pigments: A Handbook of Their History and Characteristics; Feller, R.L., Ed.; Cambridge University Press: Cambridge, UK, 1986; pp. 65-108.

17. Kolkena, L.; Blok, V.; van der Berg, K.J.; Megens, L.; Keune, K.; van Loon, A. A phenomenological atlas of degraded cadmi-um yellow oil paint in paintings by Piet Mondrian and some of his contemporaries. In Proceedings of the ICOM-CC 17th Triennial Conference Preprints, Melbourne, Australia, 15-19 September 2014.

18. Van der Snickt, G.; Dik, J.; Cotte, M.; Janssens, K.; Jaroszewicz, J.; De Nolf, W.; Groenewegen, J.; Van der Loeff, L. Characterization of a Degraded Cadmium Yellow (CdS) Pigment in an Oil Painting by Means of Synchrotron Radiation Based X-ray Techniques. Anal. Chem. 2009, 81, 2600-2610. [CrossRef] [PubMed]

19. Hines, D.A.; Becker, M.A.; Kamat, P.V. Photoinduced Surface Oxidation and Its Effect on the Exciton Dynamics of CdSe Quantum Dots. J. Phys. Chem. C 2012, 116, 13452-13457. [CrossRef]

20. Katari, J.E.B.; Colvin, V.L.; Alivisatos, A.P. X-ray Photoelectron Spectroscopy of CdSe Nanocrystals with Applications to Studies of the Nanocrystal Surface. J. Phys. Chem. 1994, 98, 4109-4117. [CrossRef]

21. Bischof, T.; Ivanda, M.; Lermann, G.; Materny, A.; Kiefer, W.; Kalus, J. Linear and Nonlinear Raman Studies on CdSxSe1-x Doped Glasses. J. Raman Spectrosc. 1996, 27, 297-302. [CrossRef]

22. Krishnamurti, D. The Raman spectrum of rutile. Proc. Math. Sci. 1962, 55, 290-299. [CrossRef]

23. Laver, M. Titanium Dioxide Whites. In Artists' Pigments: A Handbook of Their History and Characteristics; West Fitz-Hugh, E., Ed.; Oxford University Press: Oxford, UK, 1997; pp. 295-355.

24. Koob, S. The Conservation and Restoration of Greek Vases: Loss Compensation for Publication and Museum Display. In Konservieren Oder Restaurieren: Die Restaurierung Griechischer Vasen von der Antike bis Heute; Beihefte zum Corpus Vasorum Antiquorum Band III; Verlag C. H. Beck: Munich, Germany, 2007; pp. 113-117.

25. Lafuenete, B.; Downs, R.T.; Yang, Y.; Stone, N. The power of databases: The RRUFF project. In Highlights in Mineralogical Crystallography; Armbruster, T., Danisi, R.M., Eds.; W. De Gruyter: Berlin, Germany, 2015; pp. 1-30. Available online: https: / / rruff.info (accessed on 9 June 2021).

26. Goldan, A.H.; Li, C.; Pennycook, S.J.; Schneider, J.; Blom, A.; Zhao, W. Molecular structure of vapor-deposited amorphous selenium. J. Appl. Phys. 2016, 120, 135101. [CrossRef]

27. Bube, R.H.; Thomsen, S.M. Photoconductivity and Crystal Imperfections in Cadmium Sulfide Crystals. Part I. Effect of Impurities. J. Chem. Phys. 1955, 23, 15-17. [CrossRef] 